\title{
Sampling techniques for the assessment of anthropogenic vapour and particulate mercury in the Brazilian Amazon atmosphere
}

\author{
Rozane V. Marins, $\dagger^{a}$ Jailson B. de Andrade, ${ }^{* b}$ Pedro A. de P. Pereira, ${ }^{b}$ Elizabeth C. Paiva ${ }^{a}$ \\ and Heloisa H. M. Paraquettit ${ }^{a}$ \\ ${ }^{a}$ Centro de Tecnologia Mineral, CETEM/CNPq, Rua 4, Quadra D, Ilha do Fundão, Rio de \\ Janeiro, RJ, 21941-590, Brazil \\ ${ }^{b}$ Instituto de Química, Universidade Federal da Bahia, Campus Universitário de Ondina, \\ Salvador, BA, 40170-290, Brazil.E-mail: jailsong@ufba.br
}

Received 21st January 2000, Accepted 12th May 2000

Published on the Web 29th June 2000

A system, based on annular gold-coated denuders, was optimized and used in the atmospheric sampling of mercury in urban and rural sites of the Alta Floresta, a region in the Brazilian Amazon. Results showed that vapour phase mercury $\left(\mathrm{Hg}_{\mathrm{v}}\right)$ is dominant in samples collected in both sites. However, particulate mercury $(\mathrm{Hg})$ may sometimes be significant at the urban site, with values representing up to $77 \%$ of the total $\mathrm{Hg}$ collected during sampling, but may also be insignificant at the same site, depending on the gold commercialization activity and, probably, on the meteorological conditions during the sampling period. The presence of mercury in both the vapour and particulate phases in the atmosphere of the urban site can explain the high mercury concentrations found in urban dust reported for some cities in the Amazon, and also the relatively high $\mathrm{Hg}$ concentrations found in soils adjacent to the urban centre of Alta Floresta. It appears that the urban dust of "garimpo" areas in the Amazon can act as an efficient adsorber of $\mathrm{Hg}_{\mathrm{v}}$ emitted by gold dealer operations during the purification process. Mercury emissions from gold dealer shops in the Amazon have been considered as a human health risk through the inhalation of $\mathrm{Hg}$ vapour. However, although true for indoor sites, the significant contribution of particulate phase $\mathrm{Hg}$ shown in this study in outdoor urban sites calls for a reevaluation of the risk assessment estimates performed up to now in urban centres in the Amazon.

\section{Introduction}

Mercury emissions to the Amazon atmosphere resulting from gold mining reach 50-70 tonnes per year, and may represent $1-$ $6 \%$ of the global anthropogenic $\mathrm{Hg}$ emissions into the atmosphere. Elemental mercury vapour is released into the atmosphere during roasting of $\mathrm{Au}: \mathrm{Hg}$ amalgam and vaporized during the different processes of gold extraction, and also during the purification of gold for commercialization in gold dealer shops located in urban areas. This latter kind of emission is a serious public health problem in many towns in the Amazon region. ${ }^{1}$

Marins and Tonietto ${ }^{2}$ suggested that mercury emitted from the process of gold purification includes not only metallic mercury vapour but also other mercury species. This conclusion was based on the results obtained in a comparative study using three different sampling techniques for mercury in air in urban areas. These results also showed that methodologies with insufficient sensitivity could be responsible for the inaccuracy of most data on mercury concentration in the Amazon atmosphere.

Once emitted to the atmosphere, metals can be transported in the gaseous (or vapour phase), or in a solid form within or condensed onto aerosols of varying sizes. The transport of particulate phase $\mathrm{Hg}$ is generally the most significant. Transport of metals in the vapour phase depends much more on the chemical properties and emission sources of the metal concerned. ${ }^{3}$ However, the transport of metalloids, such as mercury, can be important in the vapour phase.

$\dagger$ Present address: Departamento de Geologia, Universidade Federal do Ceará, Fortaleza, CE, 60455-970, Brazil.

E-mail: 1drude@fortalnet.com.br

†Present address: Departamento de Geoquímica, Universidade Federal Fluminense, Niterói, RJ, 24020-007, Brazil.
Diffusion denuders have been used since the 1980s in the monitoring of gaseous atmospheric pollutants. Diffusion-based sampling has proven to be a reliable approach for the measurement of a gas in the presence of an aerosol, because the diffusion coefficient of a gas molecule is, in general, about four orders of magnitude larger than the smallest aerosol with a significant mass contribution to the atmosphere. ${ }^{4}$

The first diffusion-based collectors were single-channel denuders. However, Possanzini et al. ${ }^{5}$ showed that annular denuders gave a better performance.

The low atmospheric concentrations of mercury suggest that annular denuders may be useful in the evaluation of mercury contamination in gold mining areas, because they can collect large air volumes per unit time, ${ }^{4}$ and because it is possible to automate the sampling system to the final detection, by cycles of sorption and desorption of mercury from the denuders. In addition, this type of collector prevents reactions between reactive gases and the filters used in traditional samplers. ${ }^{5,6}$

Losses or gains of mercury can occur when new fluxes of air, more diluted or more concentrated in mercury, pass through the filters, or due to variations in the relative humidity $(\mathrm{RH})$ of the air or in the concentrations of other gases, such as ozone. ${ }^{7,8}$ In the Amazon region, the extraction and commercialization of gold is a rudimentary activity, and the mercury content in gold can be very different from site to site, resulting in different mercury emissions from hour to hour during a working day in gold dealer shops. Second, gold mining areas are often impacted by the burning of forests and biogenic emissions from vegetation, with associated gases and particles. Finally, the $\mathrm{RH}$ in this region can range from $20 \%$ to $99 \%$ during a single day.

The efficiency of the denuder system for mercury collection depends on several parameters, including the sampling flow rate, sampling time, coating thickness of the denuder walls and external variables such as the $\mathrm{RH}$ and temperature. One type 
that has been used for mercury sampling is the annular denuder impregnated with gold. Mercury compounds, in the gaseous phase, are collected on gold, ${ }^{9}$ or fine films of gold (50-200 $\AA$ ), deposited over an inert material, such as quartz or $\mathrm{B}_{4} \mathrm{C}$, producing small blank values. In addition, the mercury sampled can be analysed by desorption at $650{ }^{\circ} \mathrm{C}$ in an optimized flow of "mercury free" gas. ${ }^{10}$

This work presents, as its main objective, the optimization of mercury sampling with a denuder system based on a goldcoated commercial model, by evaluating the effects of temperature, RH and different air flow rates on its performance. Secondly, the applicability of the method was checked by determining vapour and particulate mercury in the atmosphere of a Brazilian Amazon region affected by gold mining operations, namely Alta Floresta, in the state of Mato Grosso. Results for vapour and particulate $\mathrm{Hg}$ are presented for this site and discussed.

\section{Experimental methods}

\section{Evaluation of the denuders}

Gold-coated annular denuders (URG-2000-30CA, No. 30; URG Co., Chappel Hill, NC, USA) were tested and optimized for mercury sampling under a standard atmosphere of $\mathrm{Hg}^{0}$ at different humidity conditions and air flow rates. The $\mathrm{Hg}^{0}$ standard atmosphere was generated by a Dynacalibrator model 450-58-YS (VICI Metronics, Santa Clara, CA, USA), which contained an enclosed mercury permeation tube. Under conditions of $30^{\circ} \mathrm{C}$ and the dilution factor that was set for the experiments, the $\mathrm{Hg}^{0}$ concentration produced was determined to be, after 21 measurements, $12.76 \pm 0.42 \mu \mathrm{g} \mathrm{Hg} \mathrm{m}^{-3}$ of air. In these tests, the mass of mercury released by the Dynacalibrator was collected, as a known volume of standard air, directly in a gold trap through amalgamation. $\mathrm{The}^{\mathrm{Hg}}{ }^{0}$ was then desorbed by heating the trap and determined by cold vapour atomic absorption spectrometry (CVAAS).

The denuder efficiency for mercury sampling and the influence of the RH were determined according to the scheme shown in Fig. 1. The clean air was passed through a water bath, before entering the permeation chamber and making up the dilution. The RH generated in this way was then determined with an RH sensor device (PACER, model DH 300, Pacer Industries Inc., WI, USA) put immediately after the trap and before the rotameter and the vacuum pump. The sensor response was checked against solutions of $\mathrm{K}_{2} \mathrm{SO}_{4}$ $(\mathrm{RH}=97 \%)$ and $\mathrm{LiCl}(\mathrm{RH}=12 \%)$, as recommended by the equipment's manual.

The gold trap or permanganate solution, placed after the denuder, was checked every $15 \mathrm{~min}$, or less when necessary, for $\mathrm{Hg}$, in order to control the beginning of metal release by the sampler. The mercury adsorbed onto the denuders under different test conditions was desorbed in a furnace at $700{ }^{\circ} \mathrm{C}$ by passage of "Hg free" air throughout. The air fluxes were then trapped onto an impinger containing an acid permanganate solution. This permanganate trap, after optimization, presented recovery efficiences of the order of $99 \%$, confirming other references. ${ }^{11-13}$

Mercurial compounds in the permanganate trap were

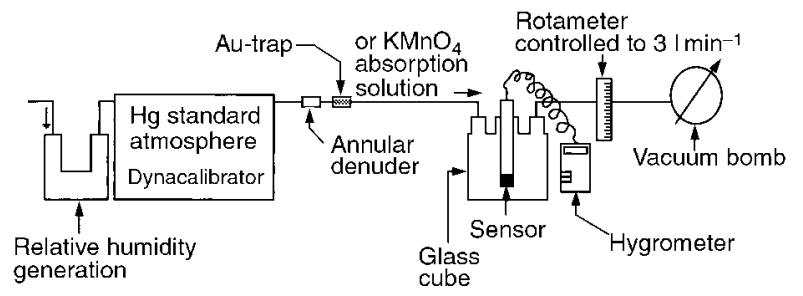

Fig. 1 Calibration system for mercury annular denuders. reduced to $\mathrm{Hg}^{0}$ by $\mathrm{SnCl}_{2}$ in acid solution and then liberated by bubbling with " $\mathrm{Hg}$ free" air. The mercury released was preconcentrated into an Au trap stage and then determined by CVAAS, as described above. The absolute detection limit for this system was around $1.0 \mathrm{ng}$ of $\mathrm{Hg}{ }^{14}$

\section{Field measurements}

After optimization of the sampling conditions, the gold-coated denuders were used in field measurements. The collection apparatus using denuders was set along with a filter cartridge. All parts of the collection system were made of quartz, Teflon or Teflon-coated material.

Two sites were studied in the field measurements: a rural area in the neighbourhood of a primary forest and the urban centre of Alta Floresta, indoors and outdoors of a gold delivery shop. These measurements were performed at different times of day and on different days, but at the same sites in the urban and rural areas. During sampling, measurements of the $\mathrm{RH}$, temperature and wind direction and velocity were carried out at $1.5-2.0 \mathrm{~m}$ from the soil surface, the height of the sampler devices.

The measurements were performed in three different ways, aiming to observe differences in the results among different collection devices. The first device was a denuder/filter system, to sample vapour and particulate mercury, respectively, with an air flow rate of $3.0 \mathrm{~L} \mathrm{~min}^{-1}$. The second device was an absorption solution of acidic potassium permanganate, to collect total mercury, at the same air flow rate. The third device was a simple filter system, to collect only particulate mercury, here named total particulate mercury, at different air flow rates to optimize the sampling time and to permit comparisons among the different sampling systems and procedures.

Several different types of filter can be used to collect particulate mercury. ${ }^{15}$ In this work, all filters used were glass fibre filters (Gelman type A/E, Gelman Sciences, Ann Arbor, MI, USA), pre-baked at $200^{\circ} \mathrm{C}$ over $12 \mathrm{~h}$, to eliminate any possible mercury contamination.

\section{Results and discussion}

The first observation made with the mercury annular denuders was that it was necessary to decontaminate them before use, because of common high blank values. Also, repeated use made them more efficient, as shown in Fig. 2. After the third desorption cycle, results for the mass of mercury retained became stable. A possible explanation of this seems to be that, when $\mathrm{Hg}$ desorbs from the denuder surface, it leaves a larger sorptive surface on the gold coating. The lifespan of the denuders had not been reached after 20 cycles, although we used a temperature of $700^{\circ} \mathrm{C}$ to desorb the mercury in each cycle.

During the evaluation of the breakthrough, it was observed that air flow rates higher than $3.0 \mathrm{~L} \mathrm{~min}^{-1}$ resulted in a rapid

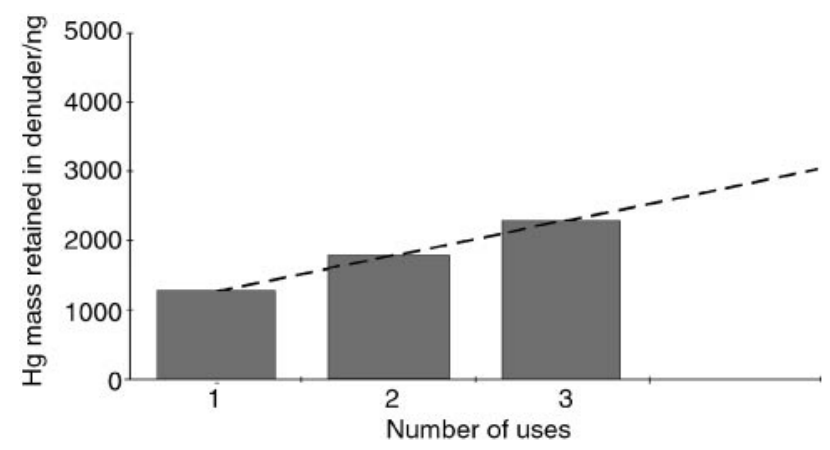

Fig. 2 Mass of mercury retained in annular denuders after three repeated uses. 


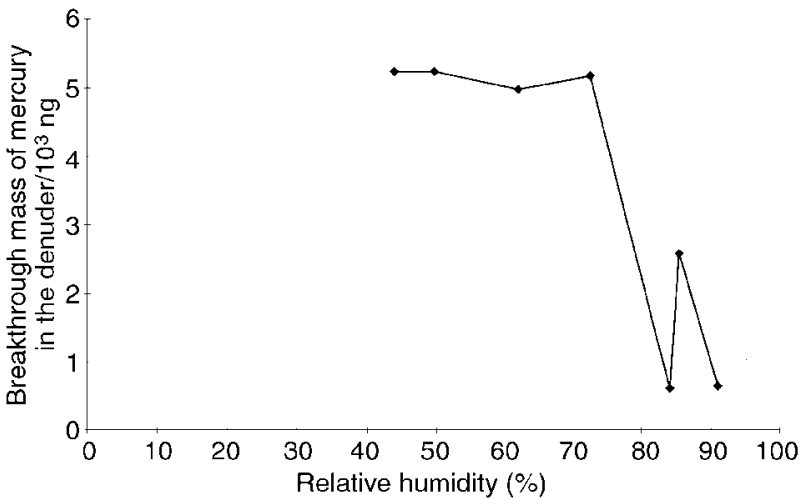

Fig. 3 Effect of relative humidity on the retained mass of mercury in annular denuders.

fall in $\mathrm{Hg}$ retention. Therefore, all tests were carried out using this flow rate. Under these conditions, the average mass of mercury retained, before breakthrough was reached, was around $5.0 \pm 0.2 \mu \mathrm{g}$.

$\mathrm{RH}$ was a key factor influencing the proper functioning of the system. Fig. 3 shows the effect of RH on the breakthrough masses of mercury in the denuder. At values between $45 \%$ and $70 \%$, retained masses were high and constant. However, at higher humidities, they decreased nearly tenfold. This suggests that water vapour may be competing with mercury for exchange sites on the gold coating.

Since the air humidity in the Amazon region can typically vary from about $60 \%$ to $98 \%$ in diurnal intervals, the operational standards established in this optimization exercise were considered to be vital to a proper sampling procedure, making it essential to measure the air humidity during sampling.

The concentrations and phase distribution of mercury in the sampling campaign in Alta Floresta are shown in Table 1. The highest mercury concentrations were found inside the gold dealer shop, followed by samples collected at the urban area. The former were up to two orders of magnitude higher than values measured at the rural site. Concentrations measured in the urban area of Alta Floresta are in the same range as those reported elsewhere ${ }^{11,12}$ for total mercury in other gold mining cities located in the Amazon. Although mercury concentrations measured at the rural site are much lower than those at the urban sites, they are still higher than that reported for pristine forest areas. ${ }^{16-19}$

Mercury in the vapour phase predominates in the atmosphere of the sampled sites. However, the relative importance of this phase to the total mercury content is different between the urban and rural areas. Today, it is generally agreed that 95$100 \%$ of the total mercury in air is in the gaseous phase, as elemental mercury, with perhaps some very minor amount of divalent mercury, with methylmercury $(\mathrm{MeHg})$ being the most likely candidate. ${ }^{20}$ The remaining mercury, the airborne particulate mercury, is important for long-range transport and mercury deposition processes and patterns. ${ }^{21}$

At the rural site, nearly $3 \mathrm{~km}$ from the downtown area, mercury in the vapour phase represented $69-100 \%$, averaging $92 \%$, of the total mercury concentration measured in the atmosphere. At the urban site, the relative importance of mercury vapour ranges between $23 \%$ and $100 \%$, averaging $66 \%$, of the total mercury concentration measured. Inside the gold dealer shop, mercury vapour nearly corresponds to all the mercury present in the atmosphere, in the range $92-99 \%$, which shows that the evaluation of its phase distribution may contribute to an appropriate selection of protective gear for the operators of the shops.

Mercury in the vapour phase ranged from 10 to $945 \mathrm{ng} \mathrm{Hg} \mathrm{m}^{-3}$ at the urban site. Since these samples were collected very close to the gold dealer shop, they may reflect the amount of gold being commercialized during the sampling period, which ranged from $300 \mathrm{~g}$ to about $4600 \mathrm{~g}$.

Also noteworthy is that the $\mathrm{RH}$ did not exceed $70 \%$.

A comparison between the total mercury concentrations measured in a $\mathrm{KMnO}_{4}$ solution and the total mercury measured as the sum of vapour and particulate $\mathrm{Hg}$ collected with the denuder system showed similar values for the rural site 1A. At the urban site, changes in the $\mathrm{KMnO}_{4}$ solution occurred, probably due to the high temperatures achieved during sampling (up to $43{ }^{\circ} \mathrm{C}$ ) rendering impossible the use of these solutions.

Similarly, $\mathrm{Hg}$ concentrations measured by sampling directly through a filter compared well with the particulate mercury measured with the denuder system for rural sites $1 \mathrm{~A}$ and $1 \mathrm{C}$ and urban site 2. During sampling at the urban site $2 \mathrm{C}$, however, the filter concentration was only $8 \mathrm{ng} \mathrm{Hg} \mathrm{m}^{-3}$ compared with $33 \mathrm{ng} \mathrm{Hg} \mathrm{m}^{-3}$ with the denuder system. This last sampling of particulate $\mathrm{Hg}$, however, was performed under relatively high air flows $\left(20 \mathrm{~L} \mathrm{~min}^{-1}\right)$, and this may have resulted in the lower efficiency of the filters for such a reactive species as mercury; more comparative samples are necessary to confirm this observation.

Larger particles containing mercury have high deposition velocities and, consequently, a lower residence time in the atmosphere, and are probably the cause of high mercury concentrations in the soil dust of urban areas in the Amazon. ${ }^{11,22,23}$ Resuspension of soil dust may also significantly affect the transport and deposition pattern of $\mathrm{Hg}$ after emission. The wind suspension of continental dust is one of the well-documented processes responsible for the introduction into the atmosphere of several constituents. ${ }^{22}$

Only mercury associated with aerosol-sized particles $<1.0 \mu \mathrm{m}$, such as, in general, trace metals, are transported into the atmosphere, ${ }^{24}$ have lower deposition velocities, and therefore have longer atmospheric residence times, making possible transfer over longer distances from the source of the

Table 1 Mercury concentrations in the atmosphere of Alta Floresta, sampled at rural and urban sites and inside a gold dealer shop

\begin{tabular}{|c|c|c|c|c|}
\hline Sampling site & $\mathrm{Hg}$ vapour/ng $\mathrm{m}^{-3}$ & Particulate $\mathrm{Hg} / \mathrm{ng} \mathrm{m}^{-3}$ & Total $\mathrm{Hg} / \mathrm{ng} \mathrm{m}^{-3}$ & Total particulate $\mathrm{Hg}^{a} / \mathrm{ng} \mathrm{m}^{-3}$ \\
\hline Rural site 1 & 185 & $<\mathrm{LOD}^{b}$ & $-^{c}$ & - \\
\hline Rural site $1 \mathrm{~A}$ & 41 & $<\mathrm{LOD}$ & 49 & $<\mathrm{LOD}$ \\
\hline Rural site 1B & 27 & $<\mathrm{LOD}$ & - & - \\
\hline Rural site $1 \mathrm{C}$ & 33 & 15 & 84 & $<\mathrm{LOD}$ \\
\hline Urban site 2 & 550 & 81 & - & 74 \\
\hline Urban site $2 \mathrm{~A}$ & 319 & 14 & - & - \\
\hline Urban site $2 \mathrm{~B}$ & 945 & $<$ LOD & - & - \\
\hline Urban site $2 \mathrm{C}$ & 10 & 33 & - & 8 \\
\hline Indoor gold dealer shop & 2372 & 44 & - & - \\
\hline Indoor gold dealer shop & 141 & 13 & - & - \\
\hline
\end{tabular}


gold delivery shops. The amount of atmospheric particles that can transport mercury over longer distances is still unknown. However, this paper represents the first contribution to an assessment of the distribution of mercury concentrations between vapour and particulate phases in rural and urban atmospheres of an Amazon region. The decrease in importance of mercury in the particulate phase in rural areas suggests that most of this form is deposited close to the source $(<10 \mathrm{~km})$. According to Lindqvist, ${ }^{25}$ approximately $50 \%$ of the anthropogenic mercury emissions are deposited 1000-2000 km from the source. However, recent estimates show that the global background is increasing by $1 \%$ per year. Therefore, resuspension of $\mathrm{Hg}$-rich particles from urban sites may be a significant source of mercury to the atmosphere, albeit non-predictable and intermittent but always active.

\section{References}

1 L. D. Lacerda and W. Salomons, Mercury in the Amazon. A Chemical Time Bomb?, Dutch Ministry of Housing, Physical Planning and Environment, Haren, 1991, p. 56.

2 R. V. Marins and G. Tonietto, in Cd-room dos Trabalhos Completos do $V$ Congresso Brasileiro de Geoquímica, ed. J. J. Abrão and R. E. Santelli, UFF/Programa de Geoquímica and Sociedade Brasileira de Geoquímica, Rio de Janeiro, Brazil, 1995.

3 P. M. Haygarth and K. C. Jones, in Biogeochemistry of Trace Metals, ed. D. C. Adriano, Lewis, Boca Raton, FL, 1992, pp. 175244.

4 P. K. Dasgupta, in Measurement Challenges in Atmospheric Chemistry, ed. L. Newman, ACS, Boston, MA, 1993, pp. 41-90.

5 M. Possanzini, A. Febo and A. Liberti, Atmos. Environ., 1983, 17, 2605.

6 B. R. Appel, in Measurement Challenges in Atmospheric Chemistry, ed. L. Newman, ACS, Boston, MA, 1993, pp. 1-40.

7 Z. F. Xiao, J. Munthe and O. Lindqvist, Water, Air Soil Pollut., 1991, 56, 141

8 A. F. Vette, G. Glinsorn, G. J. Keeler, R. Stevens and L. Stone, Int. Conf. Metals in the Environment, ed. T. C. Hutchinson, CEP Consultants, Edinburgh, 1993, pp. 340-343.
9 W. Schroeder and R. Jackson, Chemosphere, 1984, 13, 1041.

10 O. Lindqvist, A. Jernelov, K. Johansson and H. Rodhe, Mercury in the Swedish Environment. Global and Local Sources, National Swedish Environmental Protection Board, Solna, 1984, p. 105.

11 O. Malm, W. C. Pfeiffer and C. M. M. Souza, in Proc. 8th Int Conf. Heavy Metals in the Environmment, CEP Consultants, Edinburgh, 1991, vol. 1, pp. 515-518.

12 R. V. Marins, J. A. Imbassahy, W. C. Pfeiffer and W. R. Bastos, in 1st Int. Symp. Environ. Stud. Tropical Humid Forests, Biosfera, Rio de Janeiro, 1992, pp. 201-206.

13 N. Hara, Ind. Health, 1975, 13, 243.

14 G. O. Gonçalves, Instrução Técnica, IT 003, CETEM/CNPq, Rio de Janeiro, 1993, p. 6

15 R. Dumarey, R. Heindryckx and R. Dams, Anal. Chim. Acta, 1980, 116, 11

16 A. Iverfeldt, Water, Air Soil Pollut., 1991, 56, 251.

17 C. Seigneur, J. Wrobel and E. Constantimou, Environ. Sci. Technol., 1994, 28, 1589

18 G. J. Keeler, M. E. Hoyer and C. H. Lamborg, in Mercury Pollution: Integration and Synthesis, ed. C. J. Watras and J. W. Huckabee, Lewis, Boca Raton, FL, 1994, pp. 231 241.

19 R. Ferrara, B. E. Maserti, A. De Liso, H. Edner, P. Ragnarson, S. Svanberg and E. Wallinder, in Mercury Pollution: Integration and Synthesis, ed. C. J. Watras and J. W. Huckabee, Lewis, Boca Raton, FL, 1994, pp. 601-607.

20 N. S. Bloom and W. F. Fitzgerald, Anal. Chim. Acta, 1988, 208, 151

21 D. B. Porcella, in Mercury Pollution: Integration and Synthesis, ed C. J. Watras and J. W. Huckabee, Lewis, Boca Raton, FL, 1994, pp. 3-19.

22 I. Thornton, D. Cleary and S. Worthington, A Cooperative Research Study Conducted by GEDEBAM and Sol 3, GEDEBAM/Sol 3, Brazil and Switzerland, 1992, p. 45.

23 Série Tecnologia Ambiental 2, ed. L. H. Farid, CETEM/CNPq, Rio de Janeiro, 1992, p. 190

24 J. D. Thornton, S. J. Eisenreich, J. W. Munger and E. Gorhan, in Atmospheric Pollutants in Natural Waters, ed. S. J. Eisenrich, Ann Arbor Sci. Publ., Ann Arbor, MI, 1981, pp. 261-284.

25 O. Lindqvist, in Mercury Pollution: Integration and Synthesis, ed. C. J. Watras and J. W. Huckabee, Lewis, Boca Raton, FL, 1994 pp. 181-185. 